\title{
Band alignment effects at the metal electrode interface of P3HT:ZnO hybrid photovoltaics
}

\author{
SeungJin $\operatorname{Han}^{1}$, A. A. D. T.Adikaari ${ }^{1}$, K. D. G. I. Jayawardena ${ }^{1}$, N. A. Nismy ${ }^{1}$, Yoon \\ Hak Kim ${ }^{2,3}$, Jeong Won Kim ${ }^{2,3}$, Yoon-Bong $\mathrm{Hahn}^{4}$, and S. R. P. Silva ${ }^{1, \mathrm{a})}$
}

\begin{abstract}
Photoelectron spectroscopy is used to investigate the role of titanium oxide as an interfacial layer between a hybrid regioregular poly(3-hexylthiophene) (rr$\mathrm{P} 3 \mathrm{HT}): \mathrm{ZnO}$ photoactive layer and the $\mathrm{Al}$ back contact. The inspection of chemical bonds through X-ray photoemission spectroscopy core peaks indicates that the inner structure of rr-P3HT:ZnO photo-active layer is preserved (i.e. there is no chemical interaction between the active layer and the $\mathrm{TiO}_{\mathrm{x}}$ layer), despite the deposition of the $\mathrm{TiO}_{\mathrm{x}}$. Furthermore, the formation of dipoles is also observed at the interface which explains the band alignment between rr-P3HT: $\mathrm{ZnO} / \mathrm{TiO}_{\mathrm{x}} / \mathrm{Al}$. This band alignment in turn explains the enhancement in device efficiency from $1.08 \%$ to $1.22 \%$ upon incorporating the $\mathrm{TiO}_{\mathrm{x}}$ layer in rr-P3HT:ZnO photovoltaic cells.
\end{abstract}




\section{Body}

Solution processible photovoltaic cells are considered to be a promising candidate for next generation photovoltaics (PVs) due to their low cost, light weight, and ease of fabrication on flexible substrates using techniques such as spin-coating, inkjetprinting, spray-coating, and roller-casting. ${ }^{1}$ While low band gap organic semiconductors are commonly used as the donor (D), fullerene derivatives and more recently, inorganic metal oxides such as $\mathrm{ZnO}$ have been used as an acceptor (A). ${ }^{2}$ Irrespective of the acceptor used, the performance of the device depends on several key steps including photogeneration of bound electron-hole pairs or excitons, dissociation of excitons at the D-A interface, transport of the free electrons and holes in the A and D phase (respectively), and, finally the extraction of charges at the contacts. Recently, there has been a significant interest in developing interfacial layers that allow either the enhancement of the short circuit current density $\left(J_{S C}\right)$ through suitable matching of the band energies with electrode work functions or the enhancement of the open circuit voltage $\left(V_{O C}\right)$ through the formation of dipoles. ${ }^{3-5}$ Of the interfacial materials widely used, titanium oxide $\left(\mathrm{TiO}_{\mathrm{x}}\right)$ is of special interest due to its solution processible nature as well as the alignment of the conduction band of $\mathrm{TiO}_{\mathrm{x}}$ with the fullerene based A phase which will allow for efficient charge extraction. ${ }^{6}$ In this work, we have examined the enhancement of photovoltaic device performance based on rr-P3HT:ZnO bulk heterojunctions (BHJs) upon the addition of $\mathrm{TiO}_{\mathrm{x}}$ as a hole blocking layer.

The active material used in this work was prepared by adding rr-P3HT (average molecular weight, $\mathrm{Mw}=43600 \mathrm{~g} / \mathrm{mol}$ and regioregularity $=95.6 \%$; Merck Chemicals) in chlorobenzene $(14.3 \mathrm{mg} / \mathrm{ml})$ to a $0.4 \mathrm{M}$ diethylzinc solution $(0.9 \mathrm{ml}$ of a $1.1 \mathrm{M}$ diethylzinc (Sigma Aldrich) solution in toluene with $1.6 \mathrm{ml}$ of tetrahydrofuran). 
Photovoltaic devices were fabricated on ITO coated glass (Lumtec, Sheet resistance $=$ $15 \Omega / \square$ ) precleaned using acetone and methanol followed by oxygen plasma ashing. Poly(3,4-ethylenedioxythiophene) poly(styrenesulfonate) (PEDOT:PSS) (Baytron PVP AI 4083) was then spin coated at $5000 \mathrm{rpm}$ for $60 \mathrm{~s}$ and annealed at $140{ }^{\circ} \mathrm{C}$ for $15 \mathrm{~min}$ to form the hole transport layer. A $160 \mathrm{~nm}$ thick rr-P3HT:ZnO active layer was then spin cast (spin speed of $600 \mathrm{rpm}$ for $60 \mathrm{~s}$ ) on the PEDOT:PSS layer. During the spin coating process for the rr-P3HT:ZnO layer, the relative humidity within the spin coater was maintained at $40 \%$. Upon drying for $30 \mathrm{~min}$ at a relative humidity of $\sim 40 \pm 5 \%$, the samples were annealed at a $120{ }^{\circ} \mathrm{C}$ for a further $30 \mathrm{~min}$ to remove solvents. The process conditions, including the relative humidity was optimized for the best performance such that the surface defects of the $\mathrm{ZnO}$ nanostructure did not lead to significant recombination. ${ }^{7}$ A $\mathrm{TiO}_{\mathrm{x}}$ precursor solution of titanium isopropoxide diluted 1:200 in methanol prepared using the technique described by Kim et al. ${ }^{6}$ was then spin coated at $2000 \mathrm{rpm}$ for $40 \mathrm{~s}$ on the rr-P3HT:ZnO layer in nitrogen and subsequently annealed at $120{ }^{\circ} \mathrm{C}$ after aging for $30 \mathrm{~min}$. The Spin coating of PEDOT:PSS, rr-P3HT:ZnO blend and the $\mathrm{TiO}_{\mathrm{x}}$ precursor solution, as well as the thermal annealing and aging processes were carried out inside a fume cupboard. Finally, a $90 \mathrm{~nm}$ thick Al metal cathode was deposited by thermal evaporation at a base pressure of $\sim 3 \times 10^{-6}$ Torr. The PV characterisation was performed with AM 1.5G simulated irradiation using a $300 \mathrm{~W}$ Oriel simulator, calibrated to $100 \mathrm{~mW} / \mathrm{cm}^{2}$ with a Newport reference solar cell. A Keithley 2425 source meter was utilised as the electronic load.

In order to analyse the chemical and electronic properties between the rr-P3HT:ZnO layer and Al, ultra-violet photoemission spectroscopy (UPS) and X-ray photoemission spectroscopy (XPS) measurements were carried out in ultra-high vacuum. UPS and 
XPS experiments were performed using a hemispherical analyser (SES-100) system with a He I (21.2 eV) gas discharge lamp and Mg Ka X-ray source (1253.7 eV). The UPS data were recorded with a $-10 \mathrm{~V}$ bias to the sample for the work function measurement from the low kinetic energy secondary cut-offs, and $-5 \mathrm{~V}$ bias for the Highest Occupied Molecular Orbital (HOMO) and valence level analysis. In order to identify the energy band alignment and the dipole effect of a rr-P3HT:ZnO layer, a $100 \mathrm{~nm}$ thick layer of the rr-P3HT:ZnO was spin-cast at $800 \mathrm{rpm}$ for $60 \mathrm{~s}$ on a $\mathrm{Au}$ coated $\mathrm{Si}$ which was then annealed at $120{ }^{\circ} \mathrm{C}$ on a hotplate for $30 \mathrm{~min}$ after slow drying in petri-dish for 60 min. ${ }^{8}$ Thermal evaporation of $\mathrm{Al}$ was carried out on the rrP3HT:ZnO and rr-P3HT: $\mathrm{ZnO} / \mathrm{TiO}_{\mathrm{x}}$ layer. The base pressure of the deposition chamber was $5 \times 10^{-9}$ Torr. The samples were then transferred to an analysis chamber without breaking vacuum, and the UPS and XPS spectra recorded.

In order to observe the effect of the $\mathrm{TiO}_{\mathrm{x}}$ layer, we fabricated rr-P3HT thin films and rr-P3HT/TiO ${ }_{x}$ bilayer PVs with a $\mathrm{TiO}_{\mathrm{x}}$ thickness of less than $20 \mathrm{~nm}$. Comparison of the device performance under AM 1.5G irradiation indicates that the deposition of $\mathrm{TiO}_{\mathrm{x}}$ leads to an enhancement in both the short circuit current density as well as the open circuit voltage. It is noted here that the photovoltaic performance of titanium oxide/conjugated polymer bilayer device architectures have been previously reported ${ }^{9}$ and the enhancement in the $J_{S C}$ observed here is due to exciton dissociation occurring within the exciton diffusion length $(\sim 10 \mathrm{~nm})$ at the $\mathrm{rr}-\mathrm{P} 3 \mathrm{HT} / \mathrm{TiO}_{\mathrm{x}}$ interface with the poor performance devices being due to the recombination of holes as it travels through the thick rr-P3HT $(100 \mathrm{~nm})$. Previous reports on enhancement in the exciton dissociation based on Luminescence measurements have also shown improvements in the $J_{S C}$. Furthermore, once such a D/A interface is formed, the $V_{O C}$ is governed by the difference between the conduction band maximum $(\mathrm{CBM})$ of $\mathrm{TiO}_{\mathrm{x}}(\sim 4.3 \mathrm{eV})$ and the 
HOMO level of rr-P3HT ( 5.2 eV), with the observed value being comparable to that reported by Kim et al. ${ }^{6}$ However, for the device without the $\mathrm{TiO}_{\mathrm{x}}$ layer we show that the $V_{O C}$ is governed by the difference in work function of the two contacts $(4.4 \mathrm{eV}$ for Al, measured by UPS, and $4.6 \mathrm{eV}$ for ITO $)^{10}$ which leads to a negligible open circuit voltage.

Having understood that the formation of a rr-P3HT/TiO ${ }_{x}$ can lead to an enhancement in the photocurrent generation, attention is now turned towards the device performance of rr-P3HT:ZnO BHJs. In the absence of the $\mathrm{TiO}_{\mathrm{x}}$ layer, the $\mathrm{BHJ}$ hybrid cell results in a $J_{S C}$ of $3.16 \mathrm{~mA} / \mathrm{cm}^{2}$, a $V_{O C}$ at $0.598 \mathrm{~V}$, and a fill factor $(F F)$ at $57.3 \%$ with a power conversion efficiency of $1.08 \%$ under AM 1.5G irradiation. However, upon deposition of the $\mathrm{TiO}_{\mathrm{x}}$ interfacial layer, the $V_{O C}$ of a hybrid cell was observed to be significantly improved by $23 \%$ to $0.738 \mathrm{~V}$ leading to an improved power conversion efficiency of 1.22. As the rr-P3HT can also be in contact with $\mathrm{TiO}_{\mathrm{x}}$, the device architecture studied here is likely to form two cells in series, much like a pseudo tandem cell architecture, with the rr-P3HT:ZnO and rr-P3HT/TiO ${ }_{x}$ which partially explains the enhanced open circuit voltage. Furthermore, as the thermally evaporated $\mathrm{Al}$ is no longer being directly deposited onto the active material, degradation of the active layer device performance is also mitigated. The formation of two cells in series is supported by the decrease in the $F F$ to $52.7 \%$ with higher series resistance and a comparable $J_{S C}$ to the cell without the $\mathrm{TiO}_{\mathrm{x}}$ layer, which is attributed to unbalanced charge transport in the two cells. 


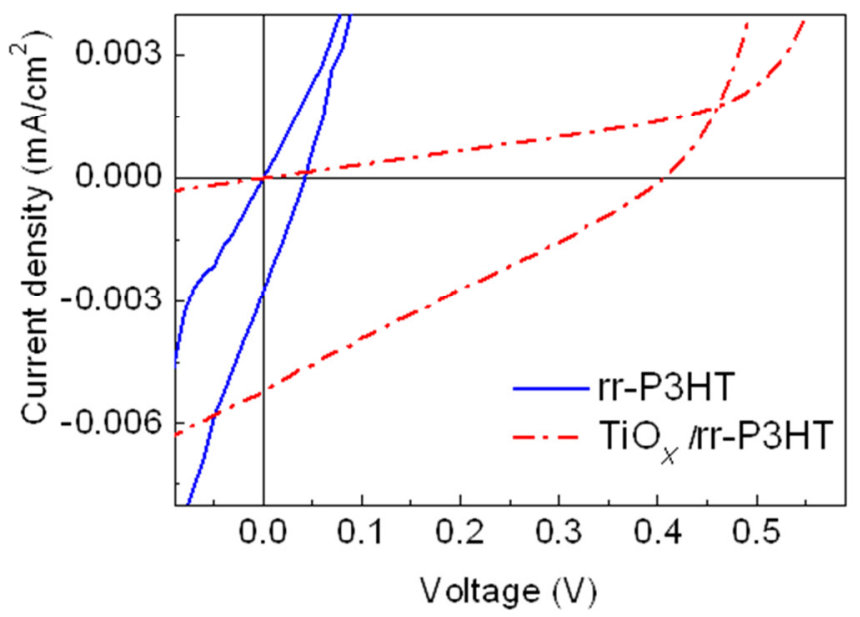

(a)

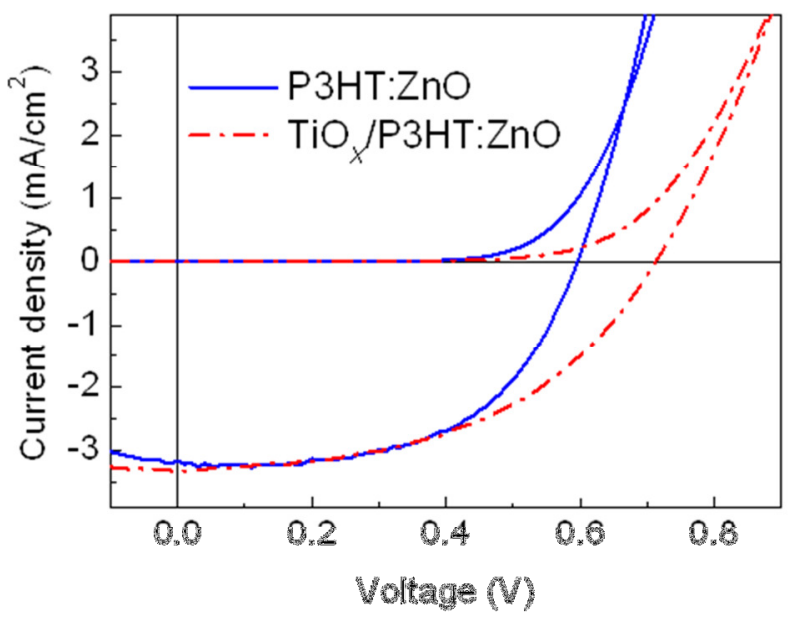

(b)

Fig. 1 Current density-voltage (J-V) characteristics of (a) devices fabricating only with a rr-P3HT without (line) and with (dash dot) the $\mathrm{TiO}_{\mathrm{x}}$ film, and (b) the best rr-P3HT:ZnO PVs with (dash dot) and without an interfacial $\mathrm{TiO}_{\mathrm{x}}$ film (lines) in the dark and under illumination with $\mathrm{AM} 1.5 \mathrm{G}$ simulated solar light.

To further improve our understanding of the effect of the $\mathrm{TiO}_{\mathrm{x}}$ buffer layer on the properties of rr-P3HT:ZnO OPV cells, XPS measurements were carried out on the active layers with and without the $\mathrm{TiO}_{\mathrm{x}}$ buffer layer. Fig. 2(a-c) shows the $\mathrm{C} 1 \mathrm{~s}, \mathrm{O} 1 \mathrm{~s}$, and $\mathrm{Ti} 2 \mathrm{p}$ XPS core level peaks of rr-P3HT:ZnO/TiO ${ }_{x}$ and rr-P3HT:ZnO layers. The peak fitting was conducted using a symmetric Gauss-Lorentz function to identify the 
contribution from the functional groups (a Shirley background subtraction was carried out). The P3HT:ZnO layer shows contribution from C-C, C-H (285 eV), C-S, C-OH $(285.7 \mathrm{eV})$ and $\mathrm{C}-\mathrm{O}(286.5 \mathrm{eV}){ }^{11-12}$ For the rr-P3HT:ZnO film, the rr-P3HT component contributes to $\mathrm{C}-\mathrm{C}, \mathrm{C}-\mathrm{H}$ and $\mathrm{C}-\mathrm{S}$ bonds while the $\mathrm{C}-\mathrm{O}$ and $\mathrm{C}-\mathrm{OH}$ bonds are derived from $\mathrm{O}$ atoms at the interfaces of the $\mathrm{rr}-\mathrm{P} 3 \mathrm{HT} / \mathrm{ZnO}$. The ratio $[(\mathrm{C}-\mathrm{C}, \mathrm{C}-$ $\mathrm{H}) /(\mathrm{C}-\mathrm{OH}, \mathrm{C}-\mathrm{S})]$ was $\sim 3$, with $\mathrm{C}-\mathrm{C}$ content at $\sim 6.27 \%$ (estimated by the percentage area of the relevant peak (peak area/total area)). Upon depositing the $\mathrm{TiO}_{\mathrm{x}}$ layer, the ratio remained unchanged. However a $\sim 15 \%$ reduction of $\mathrm{C}-\mathrm{C}, \mathrm{C}-\mathrm{H}, \mathrm{C}-\mathrm{S}$, and $\mathrm{C}-\mathrm{OH}$ contents was observed while the C-O content increased to $18.10 \%$. These ratios indicate that rr-P3HT:ZnO composite was not affected during spin-coating of the $\mathrm{TiO}_{\mathrm{x}}$ solution. The $\mathrm{O}$ atoms at the interface between the rr-P3HT: $\mathrm{ZnO} / \mathrm{TiO}_{\mathrm{x}} /$ layer contributes to the relative increment of $\mathrm{C}-\mathrm{O}$ content. $\mathrm{O} 1 \mathrm{~s}$ core level also presents similar behaviour compared to $\mathrm{C} 1 \mathrm{~s}$. The deconvolution of the $\mathrm{O} 1 \mathrm{~s}$ peak of the rrP3HT:ZnO layer reveals four peaks located at 530, 531, 531.6, and 532.6 eV, which is assigned to the $\mathrm{Zn}-\mathrm{O}$, Ti-O, $\mathrm{C}=\mathrm{O}$, and $\mathrm{C}-\mathrm{O}$ groups, respectively. ${ }^{13-16}$ For a rrP3HT:ZnO film, Zn-O, C=O, and C-O contents occupied $3.23 \%, 45.86 \%$, and $50.91 \%$, respectively. Once the additional $\mathrm{TiO}_{\mathrm{x}}$ layer is formed, the ratio of $\mathrm{C}-\mathrm{O}$ to $\mathrm{C}=\mathrm{O}$ content was similar to that in the rr-P3HT: $\mathrm{ZnO}$ layer despite the fact that $\mathrm{C}=\mathrm{O}$ and $\mathrm{C}$ O contents dropped to $17.98 \%$ and $18.80 \%$ with the presence of the Ti-O content (63.23\%). These results confirm that the rr-P3HT:ZnO BHJ is unaffected (i.e. there is no chemical interaction between the $\mathrm{TiO}_{\mathrm{x}}$ and the active layer) after spincoating the $\mathrm{TiO}_{\mathrm{x}}$ solution. This is also supported by the fact that fabricating the $\mathrm{TiO}_{\mathrm{x}}$ layer did not shift of the $\mathrm{Zn} 2 \mathrm{p}$ main peak at the binding energy of $1022.9 \mathrm{eV}$ (not shown). Furthermore, analysis of the XPS data also indicates the formation of $\mathrm{TiO}_{2}$ in a certain regions of the film, which is confirmed from the Ti $2 p$ XPS peaks. ${ }^{17}$ The Ti 
$2 \mathrm{p}$ spectra of $\mathrm{TiO}_{\mathrm{x}}$ layer on rr-P3HT:ZnO blend shows distinct spin-orbit doublets of $2 \mathrm{p}_{3 / 2}$ and $2 \mathrm{p}_{1 / 2}$. Deconvolution leads to the binding energies at $459.6 \mathrm{eV}$ for the $2 \mathrm{p}_{3 / 2}$ peak and $465.4 \mathrm{eV}$ for the $2 \mathrm{p}_{1 / 2}$, which are related to the $\mathrm{Ti}^{3+}$ state corresponding to $\mathrm{Ti}_{2} \mathrm{O}_{3}$ bond, while the peaks at $458.7 \mathrm{eV}\left(2 \mathrm{p}_{3 / 2}\right)$ and $464.3 \mathrm{eV}\left(2 \mathrm{p}_{1 / 2}\right)$ are associated with $\mathrm{Ti}$ from $\mathrm{TiO}_{2}$ (so called $\mathrm{Ti}^{4+}$ ). ${ }^{18}$ Further analysis indicates that only $37 \%$ of the $\mathrm{TiO}_{\mathrm{x}}$ layer as being occupied by the crystalline $\mathrm{TiO}_{2}$ bond. The rest of the $\mathrm{TiO}_{\mathrm{x}}$ layer consists of an amorphous structure which contributes to the poor charge transport in the photovoltaic devices. ${ }^{19}$

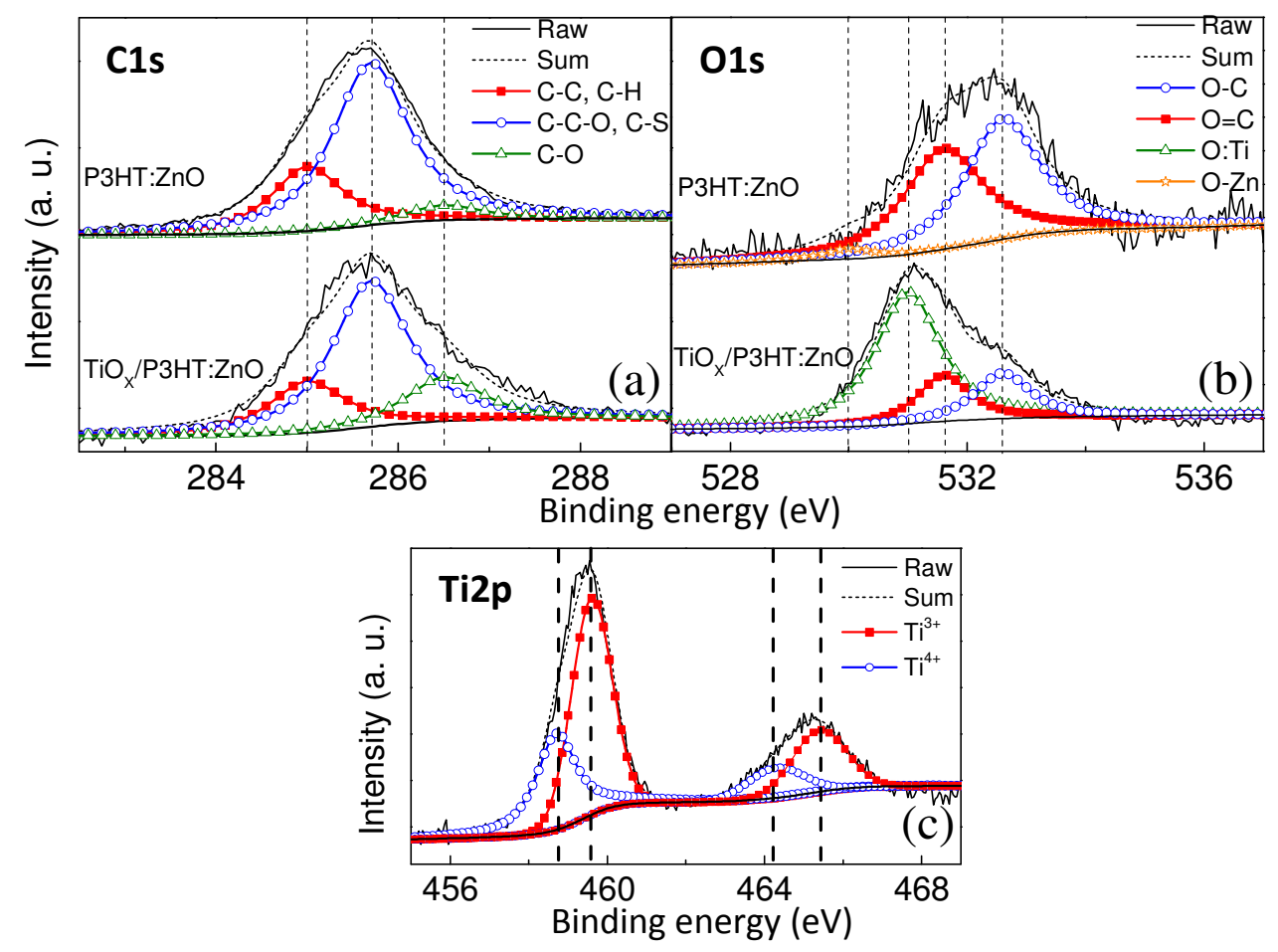

Fig.2 XPS spectra of (a) C 1s and (b) O 1s of rr-P3HT:ZnO and rr-P3HT:ZnO/TiO ${ }_{\mathrm{x}}$ layer with (c) the Ti 2p peak of rr-P3HT: $\mathrm{ZnO} / \mathrm{TiO}_{\mathrm{x}}$ layer

UPS measurements were carried out in order to observe the variation in the energy levels of rr-P3HT:ZnO/TiO ${ }_{x}$ and rr-P3HT:ZnO during the deposition of $\mathrm{Al}$ (Fig. 2 (a) $\&(d))$. We define the "onset" as the extrapolation of the leading edge on each spectrum. For rr-P3HT: $\mathrm{ZnO}$ and rr-P3HT:ZnO/TiO ${ }_{x}$ layers, the onsets of the valence 
band peaks relative to the Fermi level $E_{F}$ (binding energy, B.E. $=0 \mathrm{eV}$ ), which indicates the work function, were placed at around $4.0 \mathrm{eV}$ (Figs. 3(a) \& (c)) for both films. In principle, the work function difference between two layers indicates an interface dipole formed at the organic/metal interface (as indicated in the flat band diagrams given in Figs. 3 (e) \& (f)), which is due to the charge transfer or electron polarization upon contact of the organic molecules on the metal surface. ${ }^{20}$, the work function difference between $90 \mathrm{~nm} \mathrm{Al}$ and bare (rr-P3HT:ZnO/TiO ${ }_{\mathrm{x}}, \mathrm{rr}-\mathrm{P} 3 \mathrm{HT}: \mathrm{ZnO}$ layer) indicates the formation of interface dipoles of $0.4 \mathrm{eV}$ and $0.3 \mathrm{eV}$ for the rrP3HT: $\mathrm{ZnO} / \mathrm{Al}$ and $\mathrm{TiO}_{\mathrm{x}} / \mathrm{Al}$ interfaces respectively (As can be observed from Figures 3(c) and (d)), which can modify energy levels. Although these interface dipoles can contribute to the effective band alignment for electron extraction, a dramatic improvement in the $J_{S C}$ was not observed upon inclusion of the $\mathrm{TiO}_{\mathrm{x}}$ layer (Fig. 1 (b)). This lack of an enhancement is attributed to the lack of an increase in the dipole effect upon inserting the $\mathrm{TiO}_{\mathrm{x}}$ between $\mathrm{Al}$ and rr-P3HT:ZnO. Figs. 3 (b, d) shows the onset position of the HOMO of rr-P3HT inside rr-P3HT:ZnO to be (placed at a B.E. of 0.7 $\mathrm{eV}$ ) while the onset of the valence band of $\mathrm{TiO}_{\mathrm{x}}$ layer on rr-P3HT:ZnO was observed at a B.E. of approximately $3.3 \mathrm{eV}$. For the rr-P3HT:ZnO film, the first onset of the HOMO region represents the backbone related delocalized state of rr-P3HT with the second onset being related to the conduction band of $\mathrm{ZnO}$, mixed with the sulphur related localised states of $\mathrm{rr}-\mathrm{P} 3 \mathrm{HT} .{ }^{21}$ However, the clear onset at $0.7 \mathrm{eV}$ indicates that the top surface consists mostly of $\mathrm{P} \mathrm{HT}^{22}$, which is not favourable for electron collection at the cathode. The increase in the onset position to a B.E. of $3.5 \mathrm{eV}$ upon adding the $\mathrm{TiO}_{\mathrm{x}}$ layer is attributed to the large band gap and low-lying conduction band minimum of $\mathrm{TiO}_{\mathrm{x}}$ on the cathode side. ${ }^{6}$

The difference between the HOMO of rr-P3HT and the valance band maximum (VBM) of $\mathrm{TiO}_{\mathrm{x}}$ can contribute to effective electron extraction through hole blocking 
effect. ${ }^{23}$ However, $\mathrm{TiO}_{\mathrm{x}}$ is not only connected to $\mathrm{rr}-\mathrm{P} 3 \mathrm{HT}$ at the interface but to $\mathrm{ZnO}{ }^{2}$ At the $\mathrm{ZnO} / \mathrm{TiO}_{\mathrm{x}}$ interface, there is only a $0.2 \mathrm{eV}$ difference between the $\mathrm{VBM}$ of TiOx and the VBM of $\mathrm{ZnO}$ (a B.E. = $3.4 \mathrm{eV}$ ), which is detected by the UPS measurement of $\mathrm{ZnO} / \mathrm{Au}$ (not given). The improvement of carrier transport steming from the additional $\mathrm{TiO}_{\mathrm{x}}$ layer is restricted by the insignificant dipole effect at the interface (rr-P3HT: $\mathrm{ZnO} / \mathrm{TiO}_{\mathrm{x}}$ ) in comparison to the $40 \%$ enhancement in $J_{S C}$ reported by Kim et al for P3HT:[6,6]-phenyl C61-butyric acid methyl ester (PCBM) PVs. ${ }^{6}$ Fig. 3 also shows that for rr-P3HT:ZnO/Al, a strong shift of the Al work function is detected during the first $\mathrm{Al}$ deposition steps $(0.5 \mathrm{~nm})$. On the other hand, for $\mathrm{TiO}_{\mathrm{x}} / \mathrm{Al}$ interface, the considerable shift was noted only after deposing $4 \mathrm{~nm}$ Al. The interface dipole is produced on the rr-P3HT/Al interface of rr-P3HT:ZnO/Al layer which leads to the reduction of the $\mathrm{Al}$ work function ${ }^{20}$ and contributes to the considerable shift in first step Al evaporation on rr-P3HT:ZnO layer. Non-observation of a strong shift until the deposition of $4 \mathrm{~nm}$ of $\mathrm{Al}$ on $\mathrm{TiO}_{\mathrm{x}}$ indicates that either $\mathrm{Al}$ atoms percolate through the underlying layer or they grew into three dimensional islands at the beginning. ${ }^{24}$ Upon depositing $90 \mathrm{~nm} \mathrm{Al}$, the VBM of $\mathrm{Al}$ film fabricated on rrP3HT: $\mathrm{ZnO}$ and rr-P3HT: $\mathrm{ZnO} / \mathrm{TiO}_{\mathrm{x}}$ layer is present at $\sim 4.4 \mathrm{eV}$ which is in agreement with values given in literature (as measured by UPS). ${ }^{25}$ Based on the analysis of the UPS measurement, the energy level alignment diagrams of rr-P3HT:ZnO/Al and rrP3HT:ZnO/TiOx/Al layer structures are demonstrated in Figure 3 (e) and (f). The energy barrier between the HOMO level of P3HT and the valence band level of $\mathrm{TiO}_{X}$ contributes to the efficient hole transport in the photo-generated charge. 


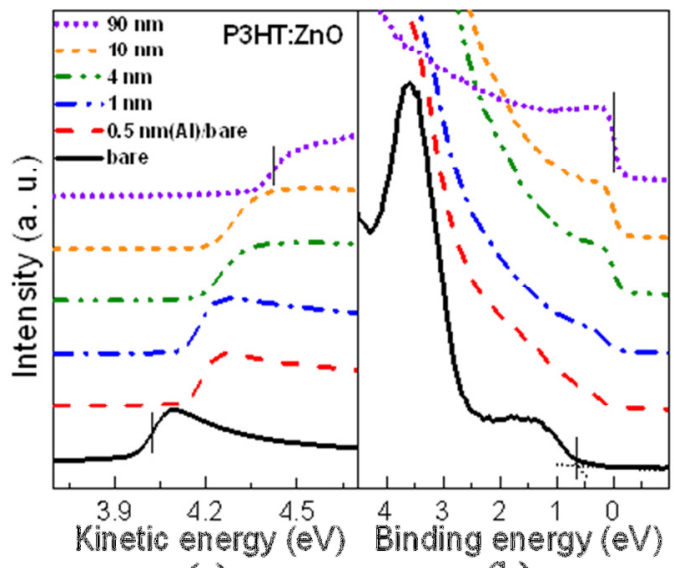

(a) (b)

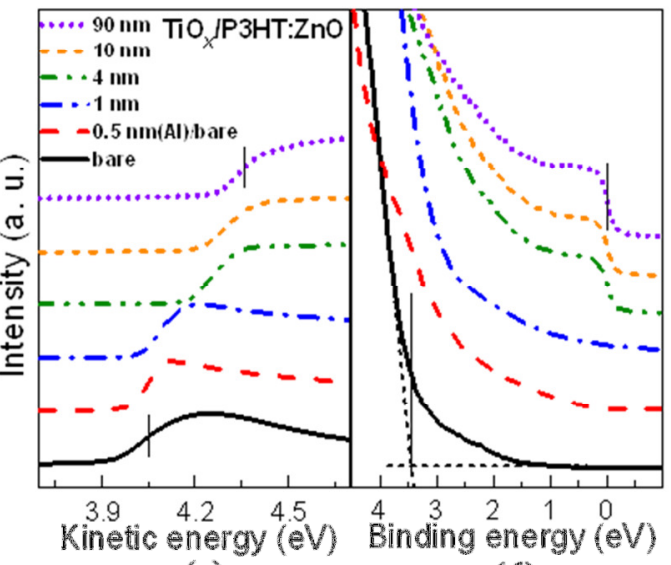

(c)

(d)

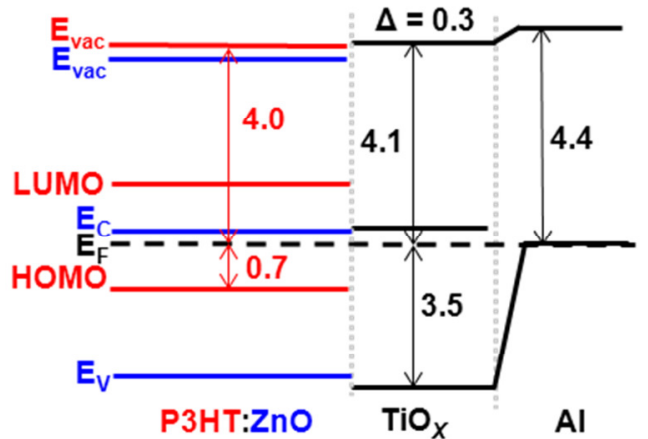

(e)

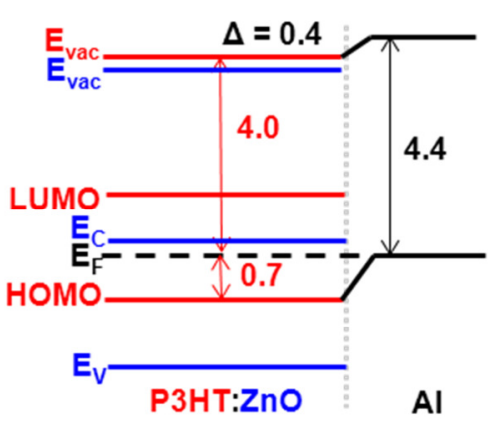

(f)

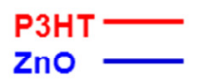

$E_{\text {vac }}$ : Vacuum level

$\mathbf{E}_{\mathrm{C}}$ : Conduction band level

$E_{\mathrm{v}}$ : Valence band level

$\mathbf{E}_{\mathrm{F}}$ : Fermi level

Fig. 3 UPS spectra of (a) work function, and (b) HOMO, valence regions for rr-P3HT:ZnO/Al interfaces depending on $\mathrm{Al}$ thickness with (c) work function and (d) valence regions for $\mathrm{TiOx} / \mathrm{Al}$ interfaces on a rr-P3HT:ZnO layer and the energy band diagram of (e) rr-P3HT:ZnO/Al and (f) rrP3HT:ZnO/TiOx/Al layer.

In conclusion, the incorporation of $\mathrm{TiO}_{\mathrm{x}}$ as a buffer layer to hybrid rr-P3HT:ZnO solar has been observed to lead to enhanced power conversion efficiency, accompanied with the improvement of the $V_{O C}$. The difference between the $\mathrm{CBM}$ of $\mathrm{TiO}_{\mathrm{x}}$ and $\mathrm{HOMO}$ of rr-P3HT in the rr-P3HT-rich region/ $/ \mathrm{TiO}_{\mathrm{x}}$ interface has contributed to the additional $V_{O C}$ of the hybrid cell. Analysis of the ratios of different chemical bonds obtained from XPS spectra indicates that the rr-P3HT:ZnO BHJ layer is safe from 
degradation during the deposition of the $\mathrm{TiO}_{\mathrm{x}}$ layer. However, the $F F$ s of the devices are observed to decreases as a result of the amorphous content of the deposited $\mathrm{TiO}_{\mathrm{x}}$ which leads to an increased series resistance. Furthermore, the $J_{S C}$ does not show significant change upon the incorporation of the $\mathrm{TiO}_{\mathrm{x}}$ interfacial layer. This lack of an enhancement in the $J_{S C}$ is attributed to the similar dipole effect in the presence and in the absence of the interfacial layer.

This work is based on a project which is funded by E.ON AG, as part of the E.ON International research Initiative. Jeong Won Kim was supported by a research project of the National Research Foundation of Korea (Grant No. 2011-0026100). The authors would also like to thank Dr Michail Beliatis and Dinesha Dabera for useful discussions. 
${ }^{1}$ Advanced Technology Institute, University of Surrey, Guildford, GU2 7XH, UK

${ }^{2}$ Korea Research Institute of Standards and Science, 267Gajeong-ro, Daejeon 305 340,Republic of Korea

${ }^{3}$ Department of Nano Science, University of Science and Technology, 217 Gajeongro, Daejeon 305-350, Republic of Korea

${ }^{4}$ School of Chemical Engineering, Chonbuk National University, Jeon-ju, Jeonbuk 561-756, Republic of Korea

${ }^{\text {a)} E l e c t r o n i c ~ m a i l: ~ s . s i l v a @ s u r r e y . a c . u k ~}$

\section{References}

1. M. D. McGehee, A. C. Mayer, S. R. Scully, B. E. Hardin, M. W. Rowell, Materials Today 10, 28, (2007).

2. S. D. Oosterhout, M. M. Wienk, S. S. van Bavel, R. Thiedmann, L. J. A. Koster, J. Gilot, J. Loos, V. Schmidt, R. A. J. Janssen, Nat. Mater. 8, 818, (2009).

3. C. F. Zhang, S. W. Tong, C. X. Zhu, C. Y. Jiang, E. T. Kang, D. S. H. Chan, Appl Phys Lett 94, 103305, (2009).

4. $\quad$ B. Kang, L. W. Tan, S. R. P. Silva, Appl. Phys. Lett., 93 , 133302, (2008).

5. A. A. D. T. Adikaari, D. M. N. M. Dissanayake, S. R. P. Silva, IEEE J. Sel. Top. Quant., 16, 1595, (2010).

6. J. Y. Kim, S. H. Kim, H. H. Lee, K. Lee, W. L. Ma, X. Gong, A. J. Heeger, Adv. Mater., 18, 572, (2006).

7. S. Han, A. A. D. T. Adikaari, K. D. G. I. Jayawardena, N. A. Nismy, S. R. P. Silva, J. Appl. Phys., 112, 066103, (2012). 
8. V. D. Mihailetchi, H. X. Xie, B. de Boer, L. M. Popescu, J. C. Hummelen, P. W. M. Blom, L. J. A. Koster, Appl. Phys. Lett. 89, 012107, (2006).

9. T. J. Savenije, J. M. Warman, A. Goossens, Chem. Phys. Lett., 287, 148, (1998).

10. Y. Park, V. Choong, Y. Gao, B. R. Hsieh, C. W. Tang, Appl. Phys. Lett., 68, 2699, (1996).

11. K. H. Lee, P. E. Schwenn, A. R. G. Smith, H. Cavaye, P. E. Shaw, M. James, K. B. Krueger, I. R. Gentle, P. Meredith, P. L. Burn, Adv. Mater., 23, 766, (2011).

12. P. G. Ren, D. X. Yan, X. Ji, T. Chen , Z. M. Li, Nanotechnology 22, 055705, (2011).

13. H. H. Wang, C. S. Me, Physica E 40, 2724, (2008).

14. R. Sharma, P. P. Das, M. Misra, V. Mahajan, J. P. Bock, S. Trigwell, A. S. Biris , M. K. Mazumder, Nanotechnology 20, 075704, (2009).

15. S. D. Gardner, C. S. K. Singamsetty, G. L. Booth, G. R. He, C. U. Pittman, Carbon 33, 587, (1995).

16. Q. Wang, D. Yang, D. M. Chen, Y. B. Wang, Z. Y. Jiang, J. Nanopart. Res., 9, 1087, (2007).

17. B. V. R. Chowdari, G. V. S. Rao, G. Y. H. Lee, Solid State Ionics, 136, 1067, (2000).

18. T. M. Pan, F. H. Chen, J. S. Jung, Appl. Phys. Lett., 96, 102904, (2010).

19. S. Kim, H. Y. Jeong, S. Y. Choi, Y. K. Choi, Appl. Phys. Lett., 97, 033508, (2010).

20. M. Knupfer, G. Paasch, J. Vac. Sci. Technol. A, 23, 1072, (2005). 
21. J. E. Lyon, A. J. Cascio, M. M. Beerbom, R. Schlaf, Y. Zhu, S. A. Jenekhe, Appl. Phys. Lett., 88, 222109, (2006).

22. Z. Xu, L. M. Chen, M. H. Chen, G. Li, Y. Yang, Appl. Phys. Lett., 95, 103301, (2009).

23. A. Hayakawa, O. Yoshikawa, T. Fujieda, K. Uehara, S. Yoshikawaa, Appl. Phys. Lett., 90, 163517, (2007).

24. H. Y. Jeong, J. Y. Lee, S. Y. Choi, J. W. Kim, Appl. Phys. Lett., 95, 162108, (2009).

25. J. H. Li, J. S. Huang, Y. Yang, Appl. Phys. Lett., 90, 173505, (2007). 